\title{
Blood-injection-injury fears: harm- vs. disgust-relevant selective outcome associations.
}

Citation for published version (APA):

de Jong, P. J., \& Peters, M. L. (2007). Blood-injection-injury fears: harm- vs. disgust-relevant selective outcome associations. Journal of Behavior Therapy and Experimental Psychiatry, 38, 263-274. https://doi.org/10.1016/j.jbtep.2006.09.001

Document status and date:

Published: 01/01/2007

DOI:

10.1016/j.jbtep.2006.09.001

Document Version:

Publisher's PDF, also known as Version of record

Document license:

Taverne

Please check the document version of this publication:

- A submitted manuscript is the version of the article upon submission and before peer-review. There can be important differences between the submitted version and the official published version of record.

People interested in the research are advised to contact the author for the final version of the publication, or visit the DOI to the publisher's website.

- The final author version and the galley proof are versions of the publication after peer review.

- The final published version features the final layout of the paper including the volume, issue and page numbers.

Link to publication

\footnotetext{
General rights Owners
rights.

- You may freely distribute the URL identifying the publication in the public portal. please follow below link for the End User Agreement:

www.umlib.nl/taverne-license

Take down policy

If you believe that this document breaches copyright please contact us at:

repository@maastrichtuniversity.nl

providing details and we will investigate your claim.
}

Copyright and moral rights for the publications made accessible in the public portal are retained by the authors and/or other copyright owners and it is a condition of accessing publications that users recognise and abide by the legal requirements associated with these

- Users may download and print one copy of any publication from the public portal for the purpose of private study or research.

- You may not further distribute the material or use it for any profit-making activity or commercial gain

If the publication is distributed under the terms of Article $25 \mathrm{fa}$ of the Dutch Copyright Act, indicated by the "Taverne" license above, 


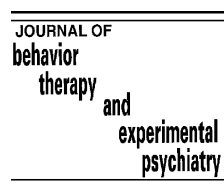

www.elsevier.com/locate/jbtep

\title{
Blood-injection-injury fears: Harm- vs. disgust-relevant selective outcome associations
}

\author{
Peter J. de Jong ${ }^{a, *}$, Madelon L. Peters ${ }^{\mathrm{b}}$ \\ ${ }^{a}$ Department of Developmental and Clinical Psychology, University of Groningen, Grote Kruisstraat 1/2, \\ 9712 TS Groningen, The Netherlands \\ ${ }^{\mathrm{b}}$ Department of Medical, Clinical, \& Experimental Psychology, Maastricht University, The Netherlands
}

\begin{abstract}
There is increasing evidence that blood-injection-injury (BII) phobia is qualitatively different from the other specific phobias in the sense that phobic distress takes the form of disgust rather than (threat-induced) fear. Following this, we tested the relative importance of harm and disgust-related associative biases in BII-fear. High $(n=25)$ and low $(n=27)$ fearful individuals saw a series of fearrelevant (blood-related) and fear-irrelevant (rabbit and flower) slides which were randomly paired with either a harm-related outcome, a disgust-related outcome, or nothing. Preexperimentally, participants expected blood-related slides to be followed by both disgust- and harm-relevant outcomes. These selective preexperimental outcome expectancies were readily corrected during the experiment. Neither low nor high fearful participants showed a postexperimental covariation bias. The absence of differential effects between high and low fearful participants does not support the idea that disgust- or harm-relevant associative biases play a role in the maintenance of BII-fears. The results corroborate the previous finding of Pury and Mineka [1997. Covariation bias for blood-injury stimuli and aversive outcomes. Behaviour Research and Therapy, 35, 35-47] that people are generally liable to selectively associate BII-stimuli with aversive outcomes.
\end{abstract}

(C) 2006 Elsevier Ltd. All rights reserved.

Keywords: Covariation bias; Expectancy bias; Blood-injection-injury phobia; Disgust; Disgust sensitivity

\footnotetext{
*Corresponding author.

E-mail address: p.j.de.jong@rug.nl (P.J. de Jong).
} 


\section{Introduction}

Covariation bias is one of the cognitive biases that is assumed to play a role in the refractoriness of phobic fears (Mineka \& Sutton, 1992). Accordingly, laboratory studies showed that individuals high in fear systematically overestimate the contingency between pictures of their feared object and aversive outcomes (e.g., Pauli, Montoya, \& Martz, 1996; Tomarken, Mineka, \& Cook, 1989). In accordance with the alleged reciprocal relationship between phobia-relevant associative biases and phobic fear, these biases have been found to be substantially reduced in treated individuals (de Jong, Merckelbach, Arntz, \& Nijman, 1992), and (residual) post-treatment covariation bias was found to be a powerful predictor of relapse after successful exposure treatment (de Jong, van den Hout, \& Merckelbach, 1995).

In apparent conflict with the idea that covariation bias is generally involved in the maintenance of specific phobias, a series of experiments testing the role of covariation bias in blood-injection-injury (BII) fears revealed that the tendency to selectively associate BIIfear-relevant stimuli (mutilated bodies, surgery, minor injuries) with aversive outcomes was not especially pronounced in BII fearful individuals (Pury \& Mineka, 1997). However, thus far studies on fear-relevant covariation bias (including the experiments of Pury and Mineka) focussed on harm/pain-relevant outcome associations. Such an approach seems appropriate when phobic distress is characterized by fear of the physical harm (e.g., snake phobia). Yet, there is increasing evidence that BII phobia is qualitatively different from the other specific phobias in the sense that strong feelings of disgust and repulsion rather than (threat-induced) fear is the dominant emotional response (Page, 1994; Sawchuk, Lohr, Westendorf, Meunier, \& Tolin, 2002; Tolin, Lohr, Sawchuk, \& Lee, 1997). Since there is evidence that affective similarity between stimuli and outcomes is an important factor in the generation of fear-relevant associative biases (e.g., Davey \& Dixon, 1996; Tomarken, Sutton, \& Mineka, 1995), it may well be that inflated disgust-related rather than harmrelated outcome associations are critically involved in BII fears.

Therefore, the present study was designed to examine whether indeed typically high BII fearful individuals show a bias to overassociate blood-related stimuli with disgust-relevant (aversive) outcomes. We used an illusory correlation paradigm that was very similar to the paradigm used in the earlier studies of Pury and Mineka (1997), with the exception that the present experiment not only included the traditionally used harm-relevant outcome (i.e., shock), but also a disgust-relevant outcome (i.e., drinking a distasting fluid) (cf. Davey, Cavanagh, \& Lamb, 2003). To index covariation bias we assessed both postexperimental covariation estimates and on-line outcome expectancies (de Jong, Merckelbach, \& Arntz, 1995). Such a procedure allows one to follow the pattern of expectancies over trials and to examine the influence of prior fear on the rate of disconfirmation of participants' expectancies.

In addition, we tested high and low BII fearful individuals' preexperimental expectancies of covariation (e.g., de Jong, 1993; McNally \& Heatherton, 1993). It has been shown in a series of studies that high fearful individuals not only tend to retrospectively overestimate the actual contingency between phobia-relevant cues and aversive outcomes, but also show a priori expectancies for phobic stimuli to be followed by aversive outcomes (e.g., Kennedy, Rapee, \& Mazurski, 1997). Even if high BII fearful individuals turn out to be very sensitive to corrective information and do not display a disgust-relevant covariation bias, they may still be characterized by a disgust-related expectancy bias. Such a bias may 
be of clinical significance as it logically instigates a pattern of avoidance behavior in phobic individuals. As a result, they will not be exposed to corrective information with regard to their expectations of catastrophical consequences to occur upon confrontation with these stimuli, which in turn will act in a way to maintain or intensify the phobic complaints.

Regardless of initial fear, we anticipated that participants would generally show a bias to overassociate blood-related stimuli with harm-relevant outcomes (cf. Pury \& Mineka, 1997), whereas disgust-related expectancy and covariation bias will differentiate (best) between high and low fearful participants (e.g., van Overveld, de Jong, \& Peters, 2006).

\section{Methods}

\subsection{Participants}

Participants were 25 highly BII fearful and 27 explicitly non-fearful first year undergraduates who received course credit for their participation. Mean age was 19.6 years $(\mathrm{SD}=1.2)$. As the vast majority of the students at the University of Groningen are women, it would be rather difficult to find sufficient male volunteers to allow for reliable evaluation of gender effects. Therefore, we preferred a homogeneous sample of female participants. Obviously, such an approach may hamper the generalizability of our results. Participants were selected on the basis of their scores on the Blood Injection-Injury Questionnaire (BIQ; Merckelbach, Muris, de Jong \& deJongh, 1999). The BIQ was part of large scale screening among all first year psychology students of the University of Groningen $(N=321)$. From those who initially indicated a willingness to participate in further research, we selected $10 \%$ of the highest and $10 \%$ of the lowest BIQ scoring individuals. Five high fear and three low fear individuals refused to participate in the present experiment.

\subsection{Assessment}

Blood Injection-Injury Questionnaire (BIQ): The BIQ (Merckelbach et al., 1999) is a 10item questionnaire containing the five BII items from the Fear Questionnaire (FQ; Marks \& Mathews, 1979) and five non-overlapping BII items from the Fear Survey Schedule (FSS; Wolpe \& Lang, 1964). The items are rated on a five-point scale with 1 indicating 'no fear' and 5 indicating 'extreme fear'. The scale has been shown to have high internal consistency (Cronbach $\alpha=.82$; Merckelbach et al., 1999; in the present sample $\alpha=.81$ ). During the day of the experiment participants also completed the BIQ-faint (Merckelbach et al., 1999), which asks respondents to indicate for all 10 situations that are covered by the BIQ how often they felt faint in this particular situation on a three point scale $(1=$ never; $2=$ sometimes; $3=$ often $)$. The internal consistency of this scale was satisfactory (Cronbach $\alpha=.86$ for the present sample).

Mutilation Questionnaire (MQ): The MQ (Klorman, Weerts, Hastings, Melamed, \& Lang, 1974) is a 30-item true-false scale measuring fear of blood and mutilation. Items cover subjective fear responses as well as overt avoidance behaviors. The instrument possesses a satisfactory reliability as indexed by its internal consistency (Cronbach $\alpha$ 's ranged from .75 to .85 in four different samples; in the present sample $\alpha=.91$ ).

Disgust Emotion Scale (DES): The DES (Walls \& Kleinknecht, 1996) is a 30-item instrument measuring aversion to injection/blood items as well as non-blood items (rotting 
foods, odors, animals). Items are scored on a scale ranging from $0=$ no aversion at all to $4=$ extreme aversion. The scale has high internal consistency and is correlated with other measures of disgust propensity (Kleinknecht, Kleinknecht, \& Thorndike, 1997). In the current sample the internal consistency of the non-blood items and the injection/blood items was satisfactory ( $\alpha$ 's being .87 and .93 , respectively).

\subsection{Stimulus materials and apparatus}

Following the illusory correlation experiment of Pury and Mineka (1997; see experiment 2) slides depicting rabbits and flowers were used as fear-irrelevant stimuli. In line with the suggestion of Pury and Mineka (1997, p. 45) we used as fear-relevant slides pictures of scenes related to blood-donation ${ }^{1}$ which have a clear positive component. We did not use surgery or mutilation slides since previous studies showed that such slides evoke relatively high levels of negative emotions even in low fearful individuals (e.g., Pury \& Mineka, 1997). There were four exemplars of each type of slide. The slides were projected onto a white screen $(80 \mathrm{~cm} \times 120 \mathrm{~cm})$, approx. $3 \mathrm{~m}$ in front of the participants. A computercontrolled beamer was used for stimulus presentation. Three types of outcomes occurred during the experiment: (a) A $500 \mathrm{~ms}$ electrical shock was used as a symbolic representation of harmful outcomes; (b) drinking $5 \mathrm{ml}$ tween-20 solution (i.e., polysorbate 20 , an innocent but bad tasting fluid; e.g., Baeyens, Crombez, De Houwer, \& Eelen, 1996) at a concentration of $5 \mathrm{ml} / \mathrm{l}$ water was used as a symbolic representation of disgusting outcomes; whereas (c) "nothing" was used as a safe outcome. Electrical shocks (ac) were delivered from a Psylab shock generator $(0-10 \mathrm{~mA})$ and administered to the middle finger of the non-dominant hand via two electrodes ( $2 \mathrm{~mm}$ diameter). The tween-20 solution was distributed via a dispenser that had to be pressed two times to fill a $10 \mathrm{ml}$ measuring glass with $5 \mathrm{ml}$ of the solution. On-line outcome expectancies were assessed after each slide presentation via a response box that was connected to a personal computer.

Before the start of the actual illusory correlation paradigm, participants were presented with a verbal description of the experiment accompanied with an exemplar of each of the three categories of slides (cf. van Overveld et al., 2006). Following this, participants were asked to indicate which part of a particular category of slides they expected to be followed by a particular outcome (the drink, the shock, or nothing) on a $100 \mathrm{~mm}$ Visual Analog Scale (VAS), ranging from 0 ('none') to 100 ('all') (e.g., "Which part of all slides depicting flowers will be followed by a shock?"). The sequence of these outcome ratings was fixed in a random order. Similar VAS scales were used following the actual experiment to index the (postexperimental) covariation estimates (e.g., "Which part of all slides depicting flowers was followed by a shock?"; see also below).

\subsection{Procedure}

Before the experiment proper, shock intensity level was determined using a shock workup procedure. Following the procedure of previous covariation bias studies (e.g., Tomarken, et al., 1989), participants were informed that it was their task to determine the relationship between categories of slides and outcomes. They were instructed that after the series of slides they would be invited to complete a questionnaire concerning the

\footnotetext{
${ }^{1}$ Slides can be obtained from the first author.
} 
relationship between slides and outcomes. In addition, they were instructed that they had to indicate outcome expectancies on a trial-by-trial basis by pressing the corresponding button on the response box (cf. Pauli, Montoya, \& Martz, 1998, 2001; Pauli, Wiedemann, \& Montoya, 1998). It was stressed that her choice had no influence on the actual outcomes. They were informed that after indicating their outcome expectancy, one of three possible instructions/messages would occur on the screen: (1) refill the measuring glass and drink the fluid; (2) press the button to administer an electrical shock; (3) nothing will happen. To familiarize participants with this procedure as well as with the respective outcomes, they were invited to (a) push the "shock" button one time before the experiment started (thereby administering themselves a shock after a $500 \mathrm{~ms}$ delay), and (b) to fill one glass and drink the solution before the experiment proper.

During the experiment, the outcome-related instructions were followed after a fixed $6 \mathrm{~s}$ interval by a message on the screen that instructed participants to press a button to continue the experiment. Intertrial intervals ranged from 5 to $15 \mathrm{~s}$. The conditional probability of any outcome given the prior occurrence of any category of slide was $1 / 3$, the probability of occurrence of each type of slide was $1 / 3$, and that of each outcome was $1 / 3$. Stimulus-outcome combinations were randomly distributed across trials, with the restriction that on two successive trials no identical stimulus-outcome combinations occurred. To cancel out order effects, six different sequences were used that were balanced across groups. Participants were exposed to 72 slides of $6 \mathrm{~s}$ duration. At the end of the experiment, participants were asked to estimate the occurrence of each outcome given the prior occurrence of each slide type. Since variations in subjective base rates across stimuli and outcomes may influence the slide/outcome covariation estimates (e.g., Arkes \& Harkness, 1983), we also determined the pattern of base rate estimates for each slide type and each type of outcomes. For all of these estimates, 100-mm VASs were used ranging from $0 \%$ to $100 \%$. For each outcome, the "covariation"-VASs were presented on the same sheet. The order of VASs was fixed.

\subsection{Data reduction}

We first computed summary measures of preexperimental and postexperimental covariation estimates to facilitate subsequent data analyses and retain optimal power (e.g., Tomarken et al., 1995). The summary measures reflect the extent to which blood stimuli are specifically associated with disgust (or harm)-related outcome associations. We used the following formula (cf. de Jong, Merckelbach, Bögels, \& Kindt, 1998):

Disgust (Expectancy of) Covariation Bias Index $=P($ fluid $/$ blood $)-P($ nothing/blood $)$ minus $\{P$ (fluid/flower) $-P$ (nothing/flower $)+P$ (fluid/rabbit) $-P($ nothing/rabbit $)\} / 2$.

Harm (Expectancy of) Covariation Bias Index $=P($ shock $/$ blood $)-P($ nothing/blood $)$ minus $\{P($ shock/flower $)-P$ (nothing/flower $)+P$ (shock/rabbit)-(nothing/rabbit $)\} / 2$.

Larger bias scores indicate larger specific judgments (expectancies) that blood-relevant slides were (will be) specifically followed by fluid (or shock). In theory scores can range from -200 (disgust/harm outcome never followed blood slides, but always followed flower and rabbit slides) to +200 (disgust/harm outcome always followed blood slides but never rabbit or flower slides).

To compute summary measures of the on-line outcome expectancies, we first calculated the percentage of trials for each type of slide on which participants indicated to expect a particular outcome (i.e., harm-related, disgust-related outcomes, and nothing), in blocks of 
four trials (displaying this particular slide). We then computed bias indices for each block of trials using a similar formula as was used for the covariation bias/expectancy data.

\section{Results}

\subsection{BII fear and disgust sensitivity}

Supporting the validity of the initial classification as high or low BII fearful individuals, the high fear group displayed significantly higher scores on both the BIQ and MQ than low fear individuals (see Table 1). Only a very small minority of the participants reported a history of fainting (e.g., three participants of the low BII fear group and six of the high BII fear group reported to have fainted at least once in one of the 10 situations covered by the BIQ-faint [i.e., a score of 2 or 3 on at least one of the 10 items]). In line with the view that disgust is somehow involved in BII-phobia, high BII fear individuals reported significantly higher scores on both the blood/injection and the non-blood items of the DES than low BII fear individuals (see Table 1), indicating that they are relatively easily disgusted by a variety of disgust elicitors.

\subsection{Expectancy of covariation}

Mean expectancies and bias indices are shown in Table 2. A 2 Outcome (harm vs. disgust $) \times 2$ Group ANOVA revealed that participants typically expected that bloody scenes would be followed by aversive outcomes: The intercept was significantly larger than zero $\left[F(1,47)=18.8, p<.001, \eta^{2}=.285\right]$. The UCS expectancy bias for blood-relevant slides was similar for both types of outcomes $\left[F(1,47)<1, \eta^{2}=.005\right]$, and independent of individuals' level of prior fear $\left[F(1,47)<1, \eta^{2}=.017\right]$. Thus, BII fearful individuals are not characterized by a relatively strong (domain-specific) expectancy bias.

\subsection{On-line outcome expectancies}

On-line bias indices are shown in Table 3 as a function of outcome, trial block, and prior fear. A 2 Outcome (shock vs. fluid) $\times 4$ Trial Block $\times 2$ Group (high vs. low fear) ANOVA,

Table 1

Mean scores on descriptive measures for high BII fearful and non-fearful women

\begin{tabular}{|c|c|c|c|c|}
\hline Measures & High fear $(n=25)$ & Low fear $(n=27)$ & $t$ & $p$ \\
\hline \multicolumn{5}{|l|}{ BII-fear } \\
\hline BIQ (10-50) & $30.7(2.0)$ & $11.9(1.0)$ & 42.4 & $<.001$ \\
\hline MQ (0-30) & $16.8(3.9)$ & $9.0(3.0)$ & 8.1 & $<.001$ \\
\hline \multicolumn{5}{|l|}{ Disgust sensitivity } \\
\hline DES $(0-120)$ & $64.6(10.8)$ & $37.6(12.3)$ & 8.4 & $<.001$ \\
\hline Non-blood items ${ }^{a}$ & $1.8(0.5)$ & $1.4(0.5)$ & 3.1 & $<.005$ \\
\hline Blood items & $2.8(0.6)$ & $0.9(0.5)$ & 11.8 & $<.001$ \\
\hline
\end{tabular}

${ }^{\text {a }}$ Since the number of blood and non-blood items is unequally distributed, mean scores rather than sum scores of the relevant items are reported here. Standard deviations appear in parentheses. BIQ = Blood Injection-Injury Questionnaire; MQ = Mutilation Questionnaire; DES = Disgust Emotion Scale. 
Table 2

Mean expectancies of covariations for all stimulus/outcome combinations as a function of prior fear level

\begin{tabular}{|c|c|c|c|c|c|c|c|c|c|c|c|}
\hline & \multicolumn{3}{|l|}{ Blood } & \multicolumn{3}{|l|}{ Rabbit } & \multicolumn{3}{|l|}{ Flower } & \multicolumn{2}{|l|}{ Index } \\
\hline & Disgust & Harm & Nothing & Disgust & Harm & Nothing & Disgust & Harm & Nothing & Disgust & Harm \\
\hline High & $66(5)$ & $62(5)$ & $28(6)$ & $40(5)$ & $38(5)$ & $57(5)$ & $37(5)$ & $30(5)$ & $58(6)$ & 57 (16) & $58(16)$ \\
\hline Low & $57(5)$ & $57(5)$ & 39 (6) & $35(5)$ & $40(5)$ & $53(5)$ & $35(5)$ & $46(5)$ & $55(6)$ & $41(16)$ & 35 (16) \\
\hline
\end{tabular}

Note: Index can range from -200 to +200 ; large index indicate larger (specific) overestimation of blood-shock (or fluid) covariation. Standard errors appear in parentheses.

Table 3

Mean on-line bias indices as a function of outcome, block of trials, and fear

\begin{tabular}{crrrrrr}
\hline & \multicolumn{2}{l}{ Disgust } & & \multicolumn{2}{l}{ Harm } & Overall \\
\cline { 2 - 3 } & High & Low & & High & Low & \\
\hline Block & & & & & \\
1 & $1.2(.8)$ & $1.7(.8)$ & & $.8(.7)$ & $.8(.6)$ & $1.1 *(.5)$ \\
2 & $-.3(.7)$ & $-.2(.7)$ & $.7(.7)$ & $-.5(.6)$ & $-.1(.4)$ \\
3 & $.2(.9)$ & $-.6(.8)$ & $-.4(.7)$ & $-1.0(.6)$ & $-.5(.5)$ \\
4 & $.4(.7)$ & $1.4(.7)$ & $-.1(.7)$ & $.9(.7)$ & $.7(.4)$ \\
\hline
\end{tabular}

Note: *Significantly larger than $0(p<.05)$. Standard errors appear in parentheses. Indexes can range from -6 (disgust- or harm-relevant outcome is never expected for the target stimulus but always expected for both other stimuli) to +6 (a particular outcome is always expected for the target stimulus but never for both other stimuli). Overall index refers to the mean of the harm and the disgust index regardless of prior fear.

showed no main effects of Outcome $\left[F(1,49)=1.08, p>.05, \eta^{2}=.022\right]$ or Group $\left[F(1,49)<1, \eta^{2}=.000\right]$, nor a significant Outcome by Group interaction $[F(1,49)<1$, $\left.\eta^{2}=.008\right]$. Moreover, the effects of Outcome and Outcome by Group were found to be similar across blocks of trials $\left[F(3,47)=1.14, p>.05, \eta^{2}=.068\right]$ and $[F(3,47)<1$, $\left.\eta^{2}=.037\right]$, respectively. Meanwhile, there was a main effect of Block $[F(1,49)=6.1$, $\left.p<.001, \eta^{2}=.279\right]$, indicating that overall participants' on-line UCS expectancy bias for aversive outcomes varied across blocks. Subsequent analyses indicated that the UCS expectancy bias only during the first block of trials was significantly larger than zero $\left[F(1,49)=5.3, p<.05, \eta^{2}=.098\right]$.

\subsection{Postexperimentally reported estimates}

Covariation indices: For both high and low BII fearful individuals, postexperimental covariation estimates as well as the bias indexes are shown in Table 4. A 2 Outcome (harmrelated vs. disgust-related) $\times 2$ Group (high vs. low fear) ANOVA revealed that the intercept did not significantly differ from zero $\left[F(1,49)<1, \eta^{2}=.002\right]$, indicating that individuals did not generally show a bias to overassociate blood stimuli with aversive outcomes. Moreover, there was no significant main effect of Outcome $\left[F(1,49)<1, \eta^{2}=.015\right]$ or Group $[F(1,49)<1$, $\left.\eta^{2}=.002\right]$, nor a significant Outcome by Group interaction $\left[F(1,49)<1, \eta^{2}=.013\right]$. Thus neither high nor low BII fearful individuals displayed a bias to retrospectively overassociate the covariation between blood-relevant slides and harm or disgust-related outcomes. 
Table 4

Mean postexperimental covariation estimates for all stimulus/outcome combinations and bias indexes as a function of prior fear level

\begin{tabular}{|c|c|c|c|c|c|c|c|c|c|c|c|}
\hline & \multicolumn{3}{|l|}{ Blood } & \multicolumn{3}{|l|}{ Rabbit } & \multicolumn{3}{|l|}{ Flower } & \multicolumn{2}{|l|}{ Index } \\
\hline & Disgust & Harm & Nothing & Disgust & Harm & Nothing & Disgust & Harm & Nothing & Disgust & Harm \\
\hline High & 49 (4) & $45(4)$ & $42(4)$ & $52(4)$ & $51(4)$ & 47 (4) & 49 (4) & $42(4)$ & $46(3)$ & $3(8)$ & 3 (9) \\
\hline Low & $43(4)$ & $43(4)$ & 38 (4) & $46(3)$ & $43(3)$ & 37 (3) & 50 (4) & $40(3)$ & 43 (3) & $-2(8)$ & $4(8)$ \\
\hline
\end{tabular}

Note: Index can range from -200 to +200 ; large index indicate larger overestimation of blood-shock (or fluid) covariation. Standard errors appear in parentheses.

Base rate estimates: A 3 Stimulus (rabbit, flower, blood) $\times 2$ Group ANOVA revealed a main effect of Stimulus $\left[F(2,48)=6.139, p<.05, \eta^{2}=.204\right]$ indicating that the base rate estimates were highest for rabbits $(M=47.5)$, and lowest for blood $(M=38.5)$, and intermediate for flowers $(M=44.4)$. This pattern of estimates was similar for both groups $\left.F(1,49)<1, \eta^{2}=.021\right]$. A 3 Outcome (shock, juice, nothing) $\times 2$ Group revealed a main effect of outcome $\left[F(1,49)=58.8, p<.001, \eta^{2}=.709\right]$ that varied as a function of Group $\left[F(1,49)=5.5, p<.01, \eta^{2}=.187\right]$. Subsequent analyses indicated that high BII fearful individuals displayed higher base rate estimations of shock outcome than low BII fearful individuals $(t[49]=2.8, p<.01 ; M=52.4$ and $M=39.7$, respectively), whereas estimates of juice outcome were similarly high $(t<1 ; M=57.0$ and 56.8, respectively), and estimates of nothing similarly accurate $(M=31.8$ and 35.4 , respectively $t<1)$. Simple effects within groups indicated that high fear individuals' juice and shock estimates were significantly higher than their nothing estimates $(t[23]=9.2, p<.001]$ and $t[23]=4.7, p<.001)$, respectively, whereas no difference was evident between shock and juice base rate estimates $(t(23)=1.2)$. Low fear individuals' juice and shock estimates were likewise significantly higher than their nothing estimates $(t[26]=6.3, p<.001$ and $t[26]=9.4, p<.001)$, respectively, whereas the difference between juice and shock was not significant $(t[26]=1.3)$.

\section{Discussion}

The major results can be summarized as follows: (a) preexperimentally, participants expected blood-related slides to be relatively often followed by disgust- as well as by harmrelevant outcomes; (b) these biased preexperimental expectancies of covariation were similar for high and low BII-fearful individuals; (c) the pattern of on-line reported expectancies revealed that differential outcome expectancies were readily corrected during the experiment; and (d) neither low nor high fearful participants showed a (outcome specific) postexperimental covariation bias. It should be acknowledged that the present study exclusively relied on female participants. Hence it remains to be seen whether similar results will emerge in a mixed sample.

\subsection{Expectancy bias}

The pattern of preexperimental expectancies of covariation clearly showed that people generally tend to associate blood-relevant stimuli with aversive outcomes. Consistent with 
the idea that disgust-related preoccupations are involved in BII-fears (e.g., Page, 1994, 2003), the present findings showed that this expectancy bias was not restricted to harmrelated outcomes but was similarly strong with respect to disgust-relevant outcomes. However, neither the disgust-relevant nor the harm-relevant expectancy bias was found to be affected by prior fear. By and large, the on-line outcome expectancies revealed a similar pattern of results. That is, participants (initially) showed a bias to expect aversive outcomes following blood-slides that was similar for harm- and disgust-relevant outcomes, and independent of participants' prior fear level.

A major aim of the present study was to test whether the absence of prior fear effects in the earlier studies of Pury and Mineka (1997) was due to the fact that they included harmrelevant rather than disgust-relevant outcomes in their illusory correlation paradigm. Clearly, the present pattern of findings does not corroborate this idea. In addition, the absence of differential effects between high and low BII fearful participants cast further doubt on the notion that disgust- or harm-relevant expectancy bias play a significant role in the maintenance of BII-fears.

In an attempt to explain the apparent absence of prior fear effects on BII-relevant selective associations, Pury and Mineka (1997) pointed to their finding that even the minor injury slides elicited significant negative emotions in low fear individuals (relative to fearirrelevant slides) which might have been sufficient to produce a covariation bias in low fear individuals. Although the blood-related stimuli that were used in the present experiment were chosen to elicit minimal distress in low BII fear individuals, and have also a clear positive component as they all depicted scenes related to blood donation, it can not be ruled out that the present blood-related slides elicited sufficient negative emotions to give rise to a general UCS expectancy bias.

\subsection{Covariation bias}

Though participants entered the present illusory correlation experiment with a differential expectancy bias, this bias appeared not particularly robust against refutation: The on-line expectancy data indicate that participants readily adjusted their initial expectancies during the random stimulus-outcome pairings. Adding to the evidence that the initial expectancies were sensitive to current situational information, participants' postexperimental covariation estimates were close to the veridical covariation and no evidence emerged to indicate that BII-fear was related to harm- or disgust-related covariation bias. Thus in apparent contrast with the earlier findings of Pury and Mineka (1997), participants in the present experiment did not display a general bias to retrospectively overestimate the covariation between blood slides and aversive outcomes.

Several explanations can be put forward to explain the absence of a postexperimental covariation bias in the present study. First, participants were found to significantly underestimate the base-rate of BII-relevant slides. Although it is not immediately evident why participants did underestimate the base rate of the fear-relevant stimuli (e.g., possibly the BII-relevant slides were not very memorable since they were selected to elicit minimal (negative) emotions; cf. Pury \& Mineka, 1997), previous research clearly showed that increasing base rates may lead to enhanced covariation bias (Arkes \& Harkness, 1983; Pauli et al., 1996). Following this, it might be argued that the selectively lower (perceived) base rates of BII slides might have weakened (or even undermined) the covariation bias effect in the present study. 
Second, the present experimental set-up differed in an important respect from the previous study of Pury and Mineka which did show a covariation bias for blood-injury stimuli and aversive outcomes. That is, the present experiment included two aversive outcomes rather than one, and both types of outcomes appeared relevant for BII-stimuli as was evidenced by the finding that preexperimentally participants expected BII-stimuli to be relatively often followed by both disgust- and harm-related outcomes. This characteristic (i.e., the presence of two competing prior expectancies of covariation) might have weakened our ability to detect harm- and/or disgust-relevant postexperimental (and online) covariation biases related to BII stimuli. Germane to this idea, the strength of spidershock covariation estimates was found to be considerably reduced after introducing an additional category of fear-relevant slides (i.e., weapons; de Jong et al., 1992). One way to explore this possibility would be to use type of outcome (harm-relevant vs. disgustrelevant) as a between subjects rather than a within subjects factor in the design of a future study.

\section{Conclusion}

The (expectancy bias) results suggest that people associate BII-stimuli not only with harm-relevant outcomes but also with disgust-relevant outcomes. Yet, the present harmand disgust-relevant associative biases appeared not particularly strong as they were readily adjusted during the random slide/outcome pairings and did not result in a bias to retrospectively overestimate the covariation between BII stimuli and aversive outcomes. Most important, no evidence emerged to indicate that disgust (or harm) related associative biases are especially pronounced in high BII fearful individuals. The absence of inflated disgust-relevant associative biases is not necessarily inconsistent with the idea that disgust is somehow critically involved in BII fears. Meanwhile, it does cast further doubt on the role of this type of associative biases in the maintenance of BII-relevant fearful preoccupations.

Future studies are necessary to test to what extent the relatively weak associative biases might have been due to the peculiarities of the present design (e.g., including two competing aversive outcomes and the on-line judgment task). Finally, it may be worthwhile to further explore whether the absence of prior fear effects in the studies on selective associations and BII-fear might be attributed to the particular outcomes that were used in these studies (i.e., electrical shock and distasting fluid). Perhaps differential associative biases between high and low BII fearful individuals do emerge when using outcomes that more directly refer to the feared symptoms of faintness rather than to physical harm or disgust. One way to test this idea would be to use $\mathrm{CO}_{2}$ inhalations as the aversive outcome (cf. Forsyth \& Eifert, 1998; Van den Bergh, Stegen, \& Van de Woestijne, 1998).

\section{Acknowledgements}

We are grateful to Ingrid Meijners, Geke Wietske, and Claudia Raschke for their contribution to the development of the present design as well as for taking care of the actual data acquisition, and finally, to Bert Hoekzema for his technical assistance. 


\section{References}

Arkes, H. R., \& Harkness, A. R. (1983). Estimates of contingency between two dichotomous variables. Journal of Experimental Psychology General, 112, 117-135.

Baeyens, F., Crombez, G., De Houwer, J., \& Eelen, P. (1996). No evidence for modulation of evaluative flavorflavor associations in humans. Learning and Motivation, 27, 200-241.

Davey, G. C. L., Cavanagh, K., \& Lamb, A. (2003). Differential aversive outcome expectancies for high- and lowpredation fear-relevant animals. Journal of Behavior Therapy and Experimental Psychiatry, 34, 117-128.

Davey, G. C. L., \& Dixon, A. L. (1996). The expectancy bias model of selective associations: The relationship of judgements of CS dangerousness, CS-UCS similarity and prior fear to a priori and a posteriori covariation assessments. Behaviour Research and Therapy, 34, 235-252.

de Jong, P. J. (1993). Covariation bias in phobia: Mere resistance to preexperimental expectancies? Behavior Therapy, 24, 447-454.

de Jong, P. J., Merckelbach, H., \& Arntz, A. (1995). Covariation bias in phobic subjects: The relationship between a priori expectancy, on-line expectancy, autonomic responding, and a posteriori contingency judgment. Journal of Abnormal Psychology, 104, 55-62.

de Jong, P. J., Merckelbach, H., Arntz, A., \& Nijman, H. (1992). Covariation detection in treated and untreated spider phobics. Journal of Abnormal Psychology, 101, 724-727.

de Jong, P. J., Merckelbach, H., Bögels, S., \& Kindt, M. (1998). Illusory correlation and social anxiety. Behaviour Research and Therapy, 36, 1063-1073.

de Jong, P. J., van den Hout, M. A., \& Merckelbach, H. (1995). Covariation bias and the return of fear. Behaviour Research and Therapy, 33, 211-213.

Forsyth, J. P., \& Eifert, G. H. (1998). Response intensity in content-specific fear conditioning comparing $20 \%$ versus 13\% CO-sub-2-enriched air as unconditioned stimuli. Journal of Abnormal Psychology, 107, $291-304$.

Kennedy, S. J., Rapee, R. M., \& Mazurski, E. J. (1997). Covariation bias for phylogenetic versus ontogenetic fearrelevant stimuli. Behaviour Research and Therapy, 35, 415-422.

Kleinknecht, R. A., Kleinknecht, E. E., \& Thorndike, R. M. (1997). The role of disgust and fear in blood and injection-related fainting symptoms. A structural equation model. Behaviour Research and Therapy,, 35, 1075-1087.

Klorman, R., Weerts, T. C., Hastings, J. E., Melamed, B. G., \& Lang, P. J. (1974). Psychometric description of some specific fear questionnaires. Behavior Therapy, 5, 401-409.

Marks, I. M., \& Mathews, A. M. (1979). Brief standard self-rating for phobic patients. Behaviour Research and Therapy, 17, 263-267.

McNally, R. J., \& Heatherton, T. F. (1993). Are covariation biases attributable to a priori expectancy biases? Behaviour Research and Therapy, 31, 653-658.

Merckelbach, H., Muris, P., de Jong, P. J., \& deJongh, A. (1999). Disgust sensitivity, blood-injection-injury fear, and dental anxiety. Clinical Psychology and Psychotherapy, 6, 279-285.

Mineka, S., \& Sutton, S. K. (1992). Cognitive biases in the emotional disorders. Psychological Science, 3, 65-69.

Page, A. C. (1994). Blood-injury phobia. Clinical Psychology Review, 14, 443-461.

Page, A. C. (2003). The role of disgust in faintness elicited by blood and injection stimuli. Journal of Anxiety Disorders, 17, 45-58.

Pauli, P., Montoya, P., \& Martz, G.-E. (1996). Covariation bias in panic-prone individuals. Journal of Abnormal Psychology, 105, 658-662.

Pauli, P., Montoya, P., \& Martz, G.-E. (2001). On-line and a posteriori covariation estimates in panic-prone individuals: Effects of a high contingency of shocks following fear-irrelevant stimuli. Cognitive Therapy and Research, 25, 23-36.

Pauli, P., Wiedemann, G., \& Montoya, P. (1998). Covariation bias in flight phobics. Journal of Anxiety Disorders, $12,555-565$.

Pury, C. L. S., \& Mineka, S. (1997). Covariation bias for blood-injury stimuli and aversive outcomes. Behaviour Research and Therapy, 35, 35-47.

Sawchuk, C. N., Lohr, J. M., Westendorf, D. H., Meunier, S. A., \& Tolin, D. F. (2002). Emotional responding to fearful and disgusting stimuli in specific phobia. Behaviour Research and Therapy, 40, 1031-1046.

Tolin, D. F., Lohr, J. M., Sawchuk, C. N., \& Lee, T. C. (1997). Disgust and disgust sensitivity in blood-injectioninjury and spider phobia. Behaviour Research and Therapy, 35, 949-953. 
Tomarken, A. J., Mineka, S., \& Cook, M. (1989). Fear-relevant selective associations and covariation bias. Journal of Abnormal Psychology, 98, 381-394.

Tomarken, A. J., Sutton, S. K., \& Mineka, S. (1995). Fear-relevant illusory correlations: What types of associations promote judgmental bias? Journal of Abnormal Psychology, 104, 312-326.

Van den Bergh, O., Stegen, K., \& Van de Woestijne, K. P. (1998). Memory effects on symptom reporting in a respiratory learning paradigm. Health Psychology, 17, 241-248.

van Overveld, W. J. M., de Jong, P. J., \& Peters, M. L. (2006). Differential UCS expectancy bias in spider phobia: Evidence towards an association of spiders with disgust-outcomes. Journal of Behavior Therapy and Experimental Psychiatry, 37, 60-72.

Walls, M.M., \& Kleinknecht, R.A. (1996). Disgust factors as predictors of blood-injury fear and fainting. Paper presented to the Annual Meeting of the Western Psychological Association, San Jose (April).

Wolpe, J., \& Lang, P. J. (1964). A fear of survey schedule for use in behaviour therapy. Behaviour Research and Therapy, 2, 27-30. 